\title{
ADAPTAÇÃO BASEADA EM ECOSSISTEMAS: DESAFIOS PARA REDUÇÃO DE RISCOS ASSOCIADOS À MUDANÇA DO CLIMA NA MATA ATLÂNTICA DO EXTREMO SUL DA BAHIA
}

\author{
AUTOR: FERNANDA MOREIRA TIGRE \\ CO-AUTOR/ORIENTADOR: GUINEVERRE ALVAREZ MACHADO DE MELO GOMES
}

Resumo: Dentre os esforços internacionais na busca por soluções aos efeitos adversos das mudanças climáticas, está a Agenda 2030 da ONU, com seu Objetivo de Desenvolvimento Sustentável 13 para combater a mudança do clima. Neste cenário, a Adaptação baseada em Ecossistemas (AbE) é uma opção em áreas como a Mata Atlântica, a fim de reduzir a vulnerabilidade humana à mudança do clima. Assim, este trabalho buscou retratar de que forma o Programa Arboretum, de Teixeira de Freitas, contribui para a capacidade adaptativa às mudanças climáticas de sistemas socioecológicos locais a partir de suas ações de conservação e restauração florestal. Para tanto, buscou-se (i) identificar na literatura os impactos das mudanças climáticas no extremo sul da Bahia a partir dos usos e mudanças de uso da terra; (ii) conhecer ações do Programa Arboretum que contribuam para reforçar a capacidade adaptativa nos núcleos pesquisados; (iii) verificar in loco esta capacidade adaptativa dos Núcleos pesquisados. Os resultados apontam que, em relação ao histórico de uso e ocupação do solo na região do Extremo Sul da Bahia (1985-2017), observou-se aumento de áreas de "floresta plantada" e diminuição da área de pastagem em municípios como lbirapuã e Teixeira de Freitas. Em visitas de campo a três núcleos do Arboretum percebeu-se que há pouco conhecimento sobre a necessidade de adaptação aos efeitos das mudanças climáticas. Este estudo ainda encontra-se em desenvolvimento.

Palavras-chave: Mudanças climáticas, Adaptação baseada em Ecossistemas, Mata Atlântica. 